PostgRAD. MED. J. (1966), 42, 195.

\title{
THE TREATMENT OF HYPERTENSION
}

\author{
M. Hamilton, M.D., M.R.C.P. \\ From the Chelmsford Group of Hospitals.
}

Selection of Patients for Treatment

ANY PATIENT who knows that he or she has a raised blood pressure requires treatment. For the majority, this will consist only of simple measures, e.g. weight reduction, reassurance and perhaps sedation to allay apprehension. However, the minority will require treatment with potent hypotensive drugs, and the selection of patients for such treatment remains difficult. In exercising such selection, two points are important:-

(a) once started, treatment with a potent drug will be required for the rest of the patient's life, except in a small proportion of those treated, and

(b) the more time and care devoted by the doctor, and the more co-operative the patient, the better will be the results obtained.

Within a very few years of the introduction of hexamethonium, the benefits of hypotensive therapy were clearly established. The side effects produced by ganglion-blocking agents were so severe, that their administration was virtually restricted to the treatment of the complications of hypertension. However, since the introduction of thiazides, adrenergic blocking agents, and methyldopa, it has been possible to control hypertension with production of only minor side-effects from drug administration, so that the indications for treatment have broadened.

This is demonstrated by Table 1 , which illustrates the increasing proportion of patients referred to a clinic on account of a raised blood pressure, in whom treatment is started within the first three months after referral. This increase in the proportion of patients treated is partly due to the increasing appreciation of the prophylactic value of early blood pressure reduction, and partly to that of the value of thiazides used as a hypotensive agent. In my own series, the proportion of patients starting treatment with thiazides has risen from $25 \%$ in 1957 and 1958 , to $59 \%$ in 1964 (Table 2).

\section{Treatment of Complications}

Although the indications for treatment have extended, priority in respect of treatment must first be given to the presence of certain complications of hypertension, some of which are of sufficient severity as to require immediate blood pressure reduction, and consisting of: -

(a) the malignant phase

(b) hypertensive encephalopathy

(c) cardiac asthma.

The presence of papilloedema, due to hypertension, constitutes the sole physical sign to indicate that the hypertension has entered the malignant phase. This diagnosis should be regarded as a medical emergency demanding immediate introduction of hypotensive therapy, which in this instance should precede investigation into the aetiology of the raised blood pressure. There is one exception to this dogma, viz: that should a phaeochromocytoma be seriously considered as the cause of the hypertension, investigation should precede treatment. I personally still employ parenteral therapy in the initiation of treatment in such cases, using parenteral pentolinium, in order to establis control of the blood pressure within 36 hour of diagnosis.

Hypertensive encephalopathy is a diagnosis which is frequently abused. I think that there are physicians who still maintain that a stroke, occurring during the course of hypertension, constitutes a contraindication to the use of hypotensive drugs, yet who employ such treatment, justifying their decision by diagnosing a stroke as an encephalopathic attack. I confine the diagnosis of encephalopathy to an attack of confusion and severe headache, often with minor focal neurological signs, proceeding to epileptiform fits and coma. The distinction from cerebral haemorrhage can be difficult, and in my experience, often made only in retrospect, following the patient's dramatic recovery with reduction of the blood pressure.

The relief of pulmonary oedema due to hypertensive left ventricular failure, by parenteral pentolinium or methyldopa, can be quite dramatic.

The significance of the soft retinal exudate $\frac{0}{\mathbb{D}}$ must now be accepted as indicating the $\stackrel{\mathcal{f}}{+}$ development of hypertensive vascular damage $\frac{T}{0}$ (Hodge and Dollery, 1964). If therefore, the finding of papilloedema constitutes an indica- 
TABLE 1

\section{PERCENTAGE OF TOTAL NUMBER OF HYPERTENSIVE PATIENTS STARTING TREATMENT} WITHIN THREE MONTHS OF REFERRAL

$\begin{array}{lccccc} & 1957 / 58 & 1959 / 60 & 1961 / 62 & 1963 & 1964 \\ \text { Total number } & 123 & 116 & 135 & 110 & 111 \\ \begin{array}{l}\text { Number treated } \\ \begin{array}{l}\text { Percentage of } \\ \text { total treated }\end{array}\end{array} & 55 & 51 & 96 & 68 & 79 \\ & 46 & 44 & 71 & 62 & 71\end{array}$

TABLE 2

PROPORTION OF PATIENTS STARTING TREATMENT WITH THIAZIDES

$\begin{array}{lccccc} & 1957 / 58 & 1959 / 60 & 1961 / 62 & 1963 & 1964 \\ \begin{array}{l}\text { Total number treated } \\ \begin{array}{l}\text { Number treated with } \\ \text { Thiazides }\end{array}\end{array} & 55 & 51 & 96 & 68 & 79 \\ \begin{array}{l}\text { Percentage of total } \\ \text { treated with } \\ \text { Thiazides }\end{array} & 14 & 15 & 53 & 36 & 47 \\ \end{array}$

tion for immediate blood pressure reduction, the finding of evidence of vascular damage provides little less urgency. The appearance of retinal exudates in a patient previously without retinopathy, or the finding of soft exudates in a newly-examined hypertensive, constitutes a need for blood pressure reduction, no less urgent than that presented by the finding of papilloedema.

Many publications have established heart failure as the main single cause of death among untreated hypertensives, accounting for between $40 \%$ and $50 \%$ of the total mortality, but one which should now no longer be considered a cause of death among treated patients. (Smith and Fowler, 1955; Smirk, 1957). Therefore, the presence of heart failure must be considered an absolute indication for blood pressure reduction, the urgency with which treatment is introduced being determined solely by the severity of the manifestation of the failure.

The association of Hypertensive and Ischaemic Heart Disease perhaps requires special mention. Eleven years ago Doyle and Kilpatrick (1954) demonstrated the relief of angina which such patients can experience. as a result of blood pressure reduction, and this is now a commonplace observation. In my own cases, over $50 \%$ of hypertensive patients with angina obtained sufficient relief by blood pressure reduction alone, to dispense entirely with trinitrin, upon which they had previously been dependent for their normal conduct of life. I consider therefore, that the presence of angina provides an added indication for the introduction of hypotensive therapy. It is furthermore my practice to recommend such reduction of blood pressure in patients with persistent hypertension following cardiac infarction. To do so appears logical; although I have no evidence of benefit from this policy, I am convinced that it does not provoke further coronary thrombosis.

Treatment has so far been recommended solely for the treatment of complications of hypertension, but obviously evidence of deterioration in the patient's condition should demand treatment before such complications become established. Thus the appearance of retinal lesions, or of clinical, radiological, or cardiographic changes of ventricular hypertrophy, or the onset and progression of dyspnoea, require that the blood pressure level be reduced in order to prevent the development of cardiac failure or deterioration into the malignant phase.

The relief of headache, due to hypertension, by blood pressure reduction, is dramatic. Admittedly, it has been shown that such headaches can be relieved by a placebo in the majority of patients (Stewart, 1953). However, if a patient is suffering severe headaches as a result of hypertension, and if such headaches 
are interfering with the patient's life, or work, or sleep, I do not consider it justifiable to withhold hypotensive therapy, even if no complications are present. If headaches are not rapidly relieved by simple measures, e.g. sedation, weight reduction and reassurance, then the blood pressure must be reduced in order to procure relief. I see no reason to depart from accepted principles of therapeutics, viz: that whenever possible it is preferable to treat the disease causing symptoms, rather than give symptomatic treatment which has no effect upon the cause of the underlying disease.

The decision to treat symptomless, uncomplicated hypertension, is one which should not be taken lightly. It is no longer adequate merely to reassure such patients as to the absence of complications. Full investigation is obligatory, aimed at the exclusion of a remedial cause for the raised blood pressure. If no such remedial cause is found, then one must decide which patients will require treatment in order to prevent the advent of complications and whether, in fact, the evidence at present available justifies the decision to embark on hypotensive therapy, in the absence of symptoms or complications, in order to prevent such complications from arising.

When the blood pressure is raised as a result of renal disease-chronic glomerulo-or pyelonephritis-I believe that early reduction of blood pressure can retard the progress of renal failure, and Moyer, Heiden, Bevey and Ford (1958) have produced evidence supporting this contention.

\section{Prevention of Complications}

The position in respect of the administration of hypotensive drugs to a patient following a stroke, is still undefined. I do not believe that there is evidence to show that blood pressure reduction, unless excessive, causes cerebral thrombosis. Of 67 patients starting treatment following a cerebral thrombosis, there have been only 15 deaths, nine of which were due to stroke, five of these being thrombotic. I consider that a cerebral thrombosis is an added indication for blood pressure reduction, provided that the stroke has left no appreciable residual physical or mental deterioration. However, the greater problem is whether blood pressure control will prevent the development of stroke if provided early in the course of the disease. For many years, the prognosis of hypertension in respect of stroke remained uncertain. Leishman (1959,
1963), by comparing consecutive series of patients, provided convincing proof of improved prognosis in this respect, but study of consecutive cases is always open to some doubt. In an attempt to resolve this prognostic dilemma, my colleagues and I (Hamilton, Thompson and Wisniewski, 1964), conducted á therapeutic trial, the object being to determine whether blood pressure reduction influenced the incidence of complications, including strokes, in patients with essential hypertension.

It was essential to include only such patients in the trial who were hypertensive, but in whom atherosclerosis was not a dominant feature, as judged by the crude criteria available to the clinician. Thus, subjects included in the trial were all aged under 60 years. None had symptoms of arterial disease-i.e. all denied angina, claudication, rest pain in the limbs, or transient symptoms suggestive of cerebrovascular insufficiency. In all, the carotid and foot pulses were palpable, no bruits were audible over the carotid or femoral arteries, and none had cardiographic changes to suggest the presence of cardiac infarction.

It was imperative that all subjects should show a sustained manometric hypertension, and those included all maintained a diastolic blood pressure of at least $110 \mathrm{~mm}$. Hg. over a period of three months' outpatient observation, entailing at least three visits to the clinic. In view of the difficulties of accurate recording of blood pressure, all readings were made to the nearest $5 \mathrm{~mm}$. of mercury.

It is clearly indefensible to include in such a trial any patient with complications of hypertension, or severe symptoms which demand treatment, at the time of their reference to the Out-patient Clinic. Thus, all the patients had been referred because of symptomless hypertension, which was in all cases considered to be essential; known causes of secondary hypertension were excluded by routine investigation, including, if necessary, renal arteriography. None showed complications of the disorder, such as papilloedema, exudates, or haemorrhages on retinal examination; there were none with clinical, radiological, or cardiographic signs of cardiac enlargement, and none had albumen or casts in the urine, on urinalysis; all had normal level of serum-urea.

Thus, all patients were under 60 , with symptomless uncomplicated benign essential hypertension. The trial was conducted over a period of six years, and no cases were included during the last two, so that all treated cases 
received a minimum of two and a maximum of six years' therapy.

After clinical examination and investigation to exclude (a) the need for immediate treatment of the hypertension on account of symptoms or complications of the disease, and (b) the presence of some other condition known to be associated with a raised arterial pressure, cases were included in the trial, and admitted to a treated or control group alternately, in order to maintain an equal number in each group. At the conclusion of the trial, three cases were rejected after perusal of their notes; one was found to have been 62 years of age at the time of his inclusion, and in the other two there were some doubt regarding the aetiology of the hypertension. Hence the numbers in the two groups do not exactly balance.

No indication was made in the patients' clinical notes of their inclusion in the trial, and the list of all participants was kept remote from the clinics and wards. This was done deliberately, in order to avoid prejudice against introducing treatment in a patient included in the control series. It was thought that if such information were available when the patients attended the clinic, it might weigh against other considerations for the introduction of hypotensive therapy should the development of symptoms or complications make such therapy desirable.

Thus, we were able to include in the trial sixty-one patients under 60 years of age, with severe, sustained, symptomless, uncomplicated benign essential hypertension, who showed no detectable evidence of atherosclerosis. These patients comprised thirty-nine females, and twenty-two males. Twenty females and ten males constituted the treated series, and nineteen females and twelve males the control series. Despite the slight discrepancy in numbers between the groups, there was no significant difference for either sex between the treated and control groups in respect of age, weight, or blood pressure.

In assessing the efficacy of blood pressure control in the treated series, the following criteria were maintained:-

Good Control implies a diastolic pressure consistently below $100 \mathrm{~mm} . \mathrm{Hg}$.

Fair Control implies the diastolic pressure maintained below $110 \mathrm{~mm}$. $\mathrm{Hg}$.

Poor Control the diastolic pressure consistently over $110 \mathrm{~mm}$. $\mathrm{Hg}$.

To consider first the male patients-all were severely hypertensive, with no significant difference in respect of age, weight or blood $\stackrel{2}{2}$ pressure between the treated and control $\underset{\infty}{2}$ groups. In all of the ten treated males, the $\stackrel{\varnothing}{\complement}$

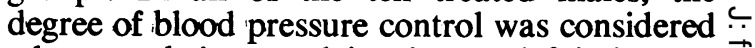
adequate, being good in nine, and fair in one. $\overrightarrow{\vec{S}}$ None suffered a stroke or other complications $\frac{\overrightarrow{0}}{0}$ of the disease. Of the twelve untreated males, $\frac{c}{0}$ four suffered a stroke; in one this proved $\frac{\bar{c}}{5}$ fatal and necropsy showed a cerebral haemorrhage. Three other patients developed $\cong$ a hemiplegia: Two of these made a complete $\stackrel{\infty}{\circ}$ objective recovery and were ultimately able $\vec{\circ}$ to resume work, but the third was left with $\overrightarrow{\vec{\omega}}$ slight dysarthria and weakness of one hand, $\stackrel{\sigma}{\sigma}$ which unfortunately prevented his return to $\bar{\nabla}$ his former occupation of schoolmaster. 3 . Although the incidence of four strokes among $\stackrel{\vec{N}}{\mathrm{~N}}$ twelve subjects appear high, the numbers are small and the difference between the two of groups is not statistically significant. Of the $\vec{\theta}$ remaining eight untreated patients, one had $\mathscr{f}$ a coronary thrombosis, with a subsequent fall 을 in blood pressure to normal levels, another began to have headaches of increasing severity and intensity, which required hypotensive drugs for their control, and in two more clinical and cardiographic signs of increasing left ventricula $\$$ hypertrophy developed, following whic hypotensive therapy was considered necessare in order to prevent the development of hypertensive cardiac failure. Thus, eight of twelve untreated patients showed complications of hypertension during the course of the trial, as compared with none of ten treated patients, and this difference is highly significant at more than the $2.5 \%$ level.

There were nineteen females in the control group, of whom three suffered a stroke-two made a full objective recovery from a presumed cerebral thrombosis; one died from rupture of an intracranial aneurysm fifteen months after starting treatment introduced to control headache of increasing severity. In five others, complications arose, consisting of coronary thrombosis in two, both with subsequent blood pressure fall; and increasing left ventricular hypertrophy in three, all of whom started treatment on this account. Thus, eight of the nineteen patients developed complications.

There were twenty females in the treated series, of whom five developed complications of the disease; consisting of a stroke in three (two cerebral thrombosis with recovery, and one fatal cerebral haemorrhage); coronary thrombosis in one, and increasing heart size in 
one. Thus, five of this series developed complications compared with eight in the control group, and clearly this difference is not significant.

However, in four of the treated group, the blood pressure control was considered poor, i.e. the diastolic pressure was never controlled below $110 \mathrm{~mm}$. Hg., which was the original criterion for inclusion in the trial. If, therefore, we consider the females, not in respect of treatment, but in respect of the adequacy of treatment, there were sixteen patients with adequate blood pressure control with only one complication (increasing L.V.), whereas of twenty-three with inadequate control (nineteen control series plus four inadequately treated) there were twelve complications, including six strokes, and this difference both in respect of the incidence of strokes and overall incidence of complications, becomes highly significant.

Thus, there is no doubt from the trial that adequate blood pressure control, maintaining the diastolic pressure below $110 \mathrm{~mm}$. $\mathrm{Hg}$., in younger patients, reduces the overall incidence of complications, including stroke. These results justify the decision to extend the indication for treatment of hypertension, so as to include patients of younger age groups in whom complications of the disease have not appeared at the time of starting treatment, in order to prevent, or delay, the appearance of such complications.

Although symptomless, all patients treated in this trial maintained a substantial hypertension, with severe diastolic pressures of over
$130 \mathrm{~mm}$. Hg. The decision to treat a sustained manometric hypertension of this magnitude, even though symptomless and uncomplicated, is not difficult to accept. But the decision to treat less severe degrees of hypertension is one which is more difficult to take. Is it in fact justifiable to treat patients with lesser grades of hypertension? Will any benefit follow the introduction of treatment in a young person, in the second or third decade of life, who maintains a diastolic blood pressure of 90-100 $\mathrm{mm}$. Hg.? I have as yet no evidence to offer on this aspect, although it has been suggested that such patients be selected according to the level of diastolic pressure, treating those whose pressure persists at levels associated with a known increased mortality. Thus, Pickering, Cranston and Pears (1964) quote the following levels of diastolic pressure which justify hypotensive therapy.

$\begin{array}{ccc}\text { Age } & \text { Male } & \text { Female } \\ \text { Under 40 years } & 106 & 115 \\ \text { Over 40 years } & 110 & 120\end{array}$

Certainly, in pregnancy, I believe that greater latitude is justified in respect of the introduction of therapy. The presence of maternal hypertension imposes a greatly increased risk of foetal death. Prior to the introduction of methyldopa, I was not successful in maintaining adequate control of blood pressure in any pregnant woman who was severely hypertensive. My facilities in this respect are restricted, but during the past three years I have been able to treat seven young women during pregnancy. All were hypertensive before pregnancy-in one the raised blood pressure

TABLE 3

INFLUENCE OF BLOOD PRESSURE CONTROL UPON COURSE OF PREGNANCY IN SEVEN HYPERTENSIVE PATIENTS

\begin{tabular}{|c|c|c|c|c|c|c|c|c|c|c|}
\hline $\begin{array}{l}\text { Age } \\
\text { Years }\end{array}$ & $\begin{array}{l}\text { Aetiology } \\
\text { of Hyper- } \\
\text { tension }\end{array}$ & $\begin{array}{c}\text { B.P. } \\
\text { preg } \\
\text { s }\end{array}$ & $\begin{array}{l}\text { efore } \\
\text { ancy } \\
\text { d }\end{array}$ & $\begin{array}{l}\text { Number of } \\
\text { pregnancies }\end{array}$ & $\begin{array}{l}\text { No. of Mis- } \\
\text { carriages }\end{array}$ & $\begin{array}{c}\text { Greatest } \\
\text { Birth } \\
\text { Weight } \\
\text { lbs. ozs. }\end{array}$ & $\begin{array}{c}\text { Duration } \\
\text { Present } \\
\text { Pregnancy } \\
\text { (Weeks) }\end{array}$ & $\begin{array}{r}\mathrm{Bi} \\
\mathrm{We} \\
\mathrm{Cl} \\
\text { lbs. }\end{array}$ & $\begin{array}{l}\text { th } \\
\text { sight } \\
\text { aild } \\
\text { ozs. }\end{array}$ & $\begin{array}{c}\text { Fate of } \\
\text { Child }\end{array}$ \\
\hline 41 & Essential & 190 & 120 & Five & 1 & $\begin{array}{ll}7 & 12\end{array}$ & 38 & 6 & 13 & Live \\
\hline 25 & $\begin{array}{c}\text { Pyelo- } \\
\text { nephritis }\end{array}$ & 180 & 110 & Two & 2 & - & 38 & 7 & 1 & Live \\
\hline 23 & $\begin{array}{c}\text { Pyelo- } \\
\text { nephritis }\end{array}$ & 160 & 120 & - & - & - & 36 & 5 & 12 & Live \\
\hline 42 & Essential & 220 & 130 & Nine & 3 & 78 & 36 & 6 & 15 & Live \\
\hline 21 & Essential & 220 & 140 & 一 & - & - & 37 & 5 & 15 & Live \\
\hline 25 & $\begin{array}{l}\text { Pyelo- } \\
\text { nephritis }\end{array}$ & 150 & 115 & Four & 2 & 74 & 38 & 5 & 14 & Live \\
\hline 21 & Vascular & 220 & 130 & - & - & - & 36 & 6 & 1 & Live \\
\hline
\end{tabular}


was atributed to renal vascular disease; in three to pyelonephritis, and the remaining three were considered to be suffering from essential hypertension. In all, the blood pressure was maintained throughout pregnancy at a diastolic level not exceeding $90 \mathrm{~mm}$. Hg. All the pregnancies were induced between the thirty-sixth and thirty-eighth week, and all were productive of a live infant of satisfactory birth weight (Table 3).

In conclusion, therefore, while therapy retains prior place in the treatment of complications of hypertension, the recent introduction of new drugs capable of achieving blood pressure control with fow side-effects has broadened the indications for the use of such drugs, so that the role of treatment in the prevention of complications of the disease is now firmly established.

\section{The Choice of Drug for Use in Treatment}

Having decided which patient requires hypotensive therapy, the choice of drug to use presents certain problems. I do not believe that any comprehensive scheme can be given whereby the treatment selected is determined by the level of blood pressure, even though this is a commonly preached dogma. It is my conviction that the most useful drug is that with which the particular physician is most familiar. All the many drugs now available for use possess certain peculiarities in respect of the method, extent and speed of the blood pressure reduction obtained, and the complications produced. Familiarity in the use of a drug can do a great deal to achieve a smooth and early response, with the production of minimal side-effects, thus making the patient's life more tolerable, and improving the prospect of continued treatment.

For the younger patient, under 40 years of age, with a mild manometric hypertension, there is at present no evidence to indicate benefit resulting from blood pressure reduction. In the absence of such evidence, it is not justifiable to commit a symptomless individual to a lifetime of drug therapy. However, this does not imply the negation of responsibility. If overweight, the achievement of weight loss will provide a reduction of blood pressure in excess of that attributable to reduction of arm circumference (Fletcher 1954). Although light sedation, e.g. with phenobarbitone, is commonly prescribed as a routine treatment for such patients with mild hypertension, there is no evidence that it produces any reduction in the level of blood pressure. However, many such patients experience symptoms due to anxiety induced by the knowledge that their blood pressure is raised, and apprehension regarding its outcome, and such sedation will frequently relieve the symptoms, through relief of anxiety. In such patients, reassurance by the physician is obligatory, and further supervision desirable in order to observe the advent of any objective evidence of deterioration, so that treatment can be instituted before complications become established or irreparable.

The need for immediate reduction of blood pressure, in the presence of certain complications of hypertension, has already been emphasised. In patients suffering from hypertensive encephalopathy, or pulmonary oedema due to hypertensive left ventricular failure, immediate reduction of blood pressure can only be achieved by parenteral preparations. In such instances I still prefer to use parenteral pentolinium (Ansolysen) given with the head of the bed elevated, in order to make full use of the postural hypotension which characterises the action of the ganglion-blocking agents. In the case of malignant hypertension, the need for such dramatic reduction of blood pressure is less urgent, but as the renal failure, in suckō cases, can progress with alarming speed, it is my choice to rely on parenteral pentolinium for the initiation of treatment in such cases. Using increasing doses of pentolinium, given by subcutaneous injection, if necessary every two hours, it is possible to reduce the blood pressure within six to eight hours, and to maintain a reasonable degree of control throughout the 24 hours, within 18 to 24 hours. Once the blood pressure has been reduced to, and maintained at, safe levels, even though the control is usually uneven with pentolinium, other oral preparations can be introduced at a later date, once the urgent complications of the disease have been overcome.

The use of thiazides, as a sole hypotensive agent, is becoming increasingly widespread, and a mode of treatment which I am using in an increasing number of patients. I personally use, purely from habit, large doses of hydroflumethiazide, giving $100 \mathrm{mg}$. twice daily, combined with potassium supplement to compensate for the increased urinary loss of potassium induced by this group of drugs. The individual dose of potassium required varies from 1 to $4 \mathrm{~g}$. potassium chloride or tartrate daily; the dose required being that 
which maintains a normal level of serum potassium.

Of over 150 patients treated with this drug alone, the average reduction of systolic and diastolic pressure has been of the order of $25 \%$ of the pre-treatment level, e.g. a mean pre-treatment blood pressure of $200 / 120$ has been reduced to one of $150 / 90$, and maintained, in some cases, for up to six years without alteration in the dose of thiazide. Unfortunately, the response to this group is unpredictablea small proportion having shown no blood pressure response at all-so that I do not use this method of treatment for patients with established complications of hypertension. However, it is simple to administer, productive of few side effects and, in my opinion, an excellent choice of drug for the elderly patient with hypertension complicated by cardiac failure, in whom the presence of extensive arterial disease is inevitable and profound falls or wide fluctuation in blood pressure are undesirable.

Reserpine is undoubtedly an effective hypotensive agent, its effect being produced mainly by noradrenaline depletion (Burn and Rand, 1957), possibly supplemented by some "central action" (McQueen, Doyle and Smirk, 1955). Although effective, reserpine causes many side effects, some of which are merely unpleasant, e.g. nasal congestion, nightmares, tremor, mental apathy, biliary colic and lactation, but two of which are extremely serious, namely, the production of sodium and fluid retention, which might precipitate cardiac failure, and the production of mental depression, which can be of such insidious onset and progression as to escape recognition before the tragedy of certification or suicide. For these reasons, I prefer to avoid the use of this drug entirely, even though, used in small doses, not exceeding $0.3 \mathrm{mg}$. a day, in conjunction with more potent hypotensive agents, it does facilitate treatment, and used in such doses, the risk of mental depression is small.

The choice of the more potent drugs is certainly one of individual preference. I consider the ganglion blocking agents as the most potent available, but the severity of side effects resulting from parasympathetic block make their administration unpleasant for the patient. However, in cases in which I cannot maintain adequate control over the blood pressure, with more recently introduced agents, I still resort to the use of mecamylamine or pempidine combined with thiazide diuretics. The hypotensive drugs made available in the $\frac{2}{z}$ past five or six years all achieve their effect $\frac{\$}{\circ}$ mainly by the depletion of noradrenaline storesc from the vessel walls. This alters the reaction of $\Rightarrow$ the vessels so that an impulse, normally vaso- $\stackrel{0}{+}$ constrictor, no longer produces this effect, but? instead causes vasodilatation. I personally have never used guanethidine with appreciable $\stackrel{5}{?}$ success. The side effects, principally muscle $\stackrel{\varnothing}{\circ}$ weakness and diarrhoea, together with the variable control over the blood pressure, $-\vec{\circ}$ which I obtain, has led me to largely abandon ${ }_{-}^{\circ}$ its use. I prefer methyldopa, which is easy $\vec{\omega}$ of administration, effective in achieving control over the blood pressure, and productive ofo few side effects, apart from drowsiness which 3 . presents a major problem to some patients (Hamilton and Kopelman, 1963). Unfortunately, I am becoming worried by the increasing proportion of patients treated with this drug, $\overrightarrow{0}$ who are developing late tolerance, as predicted 0 by Bayliss and Harvey-Smith (1962). Several ${ }^{\circ}$ patients, whose blood pressure has remained $\vec{z}$ well controlled by a fixed dose of methyldopa, over periods of eighteen to thirty-six months, 9 suddenly escape from control, and require $\vec{\circ}$ restabilisation on an alternative routine. Mo\&e recently, Bethanidine (Johnston et al, 1964) and Envacar (Peart and McMahon, 1964) haweo been reported as maintaining effective control s of the blood pressure, with the production of comparatively few side effects, and both appearo to be drugs of some considerable promise. However, my personal experience of both is $\overrightarrow{\vec{B}}$ too limited for comment.

\section{REFERENCES}

Bayliss, R. I. S., and HaRVEY-SMith, E. A. (1962): Methyldopa in the Treatment of Hypertension, Lancet, i, 763.

BURN, J. H., and RAND, M. J. (1957): Reserpine and Noradrenaline in Artery Walls, Lancet, ii, 1097.

DOYLE, A. E., and KILPATRICK, J. A. (1954): Methonium Compounds in the Angina of Hypertension, Lancet, i, 905.

FlETCHER, A. P. (1954): The Effect of Weight Reduction upon the Blood-Pressure of Obese $P$ Hypertensive Women, Quart. J. Med. N.S., 89, 331 .

Hamilton, M., and KopelmaN, H. (1963): Treatment of Severe Hypertension with Methyldopa, Brit. med.N J., i, 151.

Hamilton, M., Thompson, E. N., and WisNiEwski, T. K. M. (1964): The Role of Blood-pressure Control in Preventing Complications of Hypertension, Lancet, i, 235.

HODGE, J. V., and DOLLERY, C. T. (1964): Retinal ${ }_{0}^{\mathbb{\infty}}$ Soft Exudates, Quart. J. Med. N.S., 129, 117.

LeISHMAN, A. W. D. (1959): Hypertension-Treated and Untreated. A Study of 400 Cases, Brit. med.O J., i, 1361 . 
Leishman, A. W. D. (1963): Merits of Reducing High Blood-pressure, Lancet, i, 1284.

MCQueen, E. G., DOYle, A. E. and SMIRK, F. H. (1955): The Circulatory Effects of Reserpine, Circulation, 11, 161.

Moyer, J. H., Heider, C., Pevey, K., and Ford, R. V. (1958): The Effect of Treatment on the Vascular Deterioration Associated with Hypertension, with Particular Emphasis on Renal Function, Amer. J. Med., 24, 177.
Pickering, G. W., Cranston, W. I., and Pears, $M$. A. (1964): The Treatment of Hypertension. p. 124. Springfield, Illinois: Charles C. Thomas.

SMIRK, F. H. (1957): High Arterial Pressure p. 693. Oxford: Blackwells.

SMITH, K. S., and Fowler, P. S. B. (1955): Prevention and Treatment of Hypertensive Heartfailure by Ganglion-blocking Agents, Lancet, i, 417. STEWART, I. MCD. G. (1953): Headache and Hypertension, Lancet, i, 1261. 